\title{
Treatment of Central Sensitization in Patients With Rheumatoid Arthritis: a Narrative Overview
}

Citation for published version (APA):

Meert, L., Smeets, R. J. E. M., Baert, I., Mertens, M., Boonen, A., \& Meeus, M. (2019). Treatment of Central Sensitization in Patients With Rheumatoid Arthritis: a Narrative Overview. Current Treatment Options in Rheumatology, 5(3), 179-189. https://doi.org/10.1007/s40674-019-00125-x

Document status and date:

Published: 01/09/2019

DOI:

10.1007/s40674-019-00125-x

Document Version:

Publisher's PDF, also known as Version of record

Document license:

Taverne

Please check the document version of this publication:

- A submitted manuscript is the version of the article upon submission and before peer-review. There can be important differences between the submitted version and the official published version of record.

People interested in the research are advised to contact the author for the final version of the publication, or visit the DOI to the publisher's website.

- The final author version and the galley proof are versions of the publication after peer review.

- The final published version features the final layout of the paper including the volume, issue and page numbers.

Link to publication

\footnotetext{
General rights rights.

- You may freely distribute the URL identifying the publication in the public portal. please follow below link for the End User Agreement:

www.umlib.nl/taverne-license

Take down policy

If you believe that this document breaches copyright please contact us at:

repository@maastrichtuniversity.nl

providing details and we will investigate your claim.
}

Copyright and moral rights for the publications made accessible in the public portal are retained by the authors and/or other copyright owners and it is a condition of accessing publications that users recognise and abide by the legal requirements associated with these

- Users may download and print one copy of any publication from the public portal for the purpose of private study or research.

- You may not further distribute the material or use it for any profit-making activity or commercial gain

If the publication is distributed under the terms of Article $25 \mathrm{fa}$ of the Dutch Copyright Act, indicated by the "Taverne" license above, 


\title{
Treatment of Central Sensitization in Patients With Rheumatoid Arthritis: a Narrative Overview
}

\author{
L. Meert, PT MSc ${ }^{1,2}$
}

R. J. E. M. Smeets, MD, PhD ${ }^{3}$

I. Baert, $P T, P h D^{1,2}$

M. Mertens, $P T, M S C^{1,2}$

A. Boonen, MD, $P h D^{4}$

M. Meeus, $P T, P h D^{1,2,5, *}$

\begin{abstract}
Address
${ }^{*}, 1$ Department of Rehabilitation Sciences and Physiotherapy, University of Antwerp, Antwerp, Belgium

Email: mira.meeus@uantwerpen.be

${ }^{2}$ Pain in Motion International Research Group, Ghent, Belgium

${ }^{3}$ Department of Rehabilitation Medicine, Research School CAPHRI, Maastricht University, CIR Rehabilitation, Eindhoven, The Netherlands

${ }^{4}$ Department of Medicine, Maastricht University Medical Center, Division of Rheumatology, Maastricht, The Netherlands

${ }^{5}$ Department of Rehabilitation Sciences and Physiotherapy, Ghent University, Ghent, Belgium
\end{abstract}

Published online: 18 June 2019

(C) Springer Nature Switzerland AG 2019

This article is part of the Topical Collection on Pain in Rheumatology

Keywords Central sensitization - Chronic pain · Pain processing · Central nervous system sensitization - rheumatoid arthritis

\section{Abstract}

Purpose of review Central sensitization (CS) is present in a variety of chronic pain conditions including rheumatoid arthritis (RA). An overview of the treatment options for desensitizing the central nervous system in RA patients, with CS as their dominant pain mechanism, is provided.

Recent findings The treatment of pain in RA patients has mostly focused on treating inflammation to indirectly treat pain. Unfortunately, little research has focused on treating CS, which appears to be present in some patients with RA.

Summary "Treating the brain without ignoring the joints" should be the leading principle in the management of CS in RA patients. Pain neuroscience education, graded activity, 
and a time-contingent exercise approach are important interventions to implement in clinical practice. Further research is necessary to evaluate the effectiveness of these promising treatments for diminishing hyperexcitability of the central nervous system in RA patients with CS as their dominant pain mechanism.

\section{Introduction}

Rheumatoid arthritis (RA) is one of the most prevalent chronic inflammatory diseases affecting multiple joints, usually in a symmetrical pattern. It is characterized by joint inflammation but also by extra-articular pulmonary, cardiac or vascular, ocular, and neurological symptoms [1]. Chronic joint pain is a debilitating manifestation of RA and has shown to be the main predictor of patients' health-related quality of life [2]. Although pain in RA has traditionally been considered to be inflammatory in nature and pain is frequently used as a proxy for inflammation, the association between measures of inflammation and pain intensity is low [3-5]. Therefore, despite the success of disease-modifying antirheumatic drugs (DMARDs), many RA patients still experience pain. Koop et al. [6] for example demonstrated that, despite a relatively low RA disease activity (75\% were in DAS28 remission and 14\% had low disease activity), $44 \%$ of RA patients reported clinically significant pain (pain score $\geq 4 / 10$ ). The assumption that treatment with DMARDs will result in adequate pain management can lead to ineffective and inappropriate treatment strategies and patients may be prescribed stronger immunosuppressive medications when alternative pain management strategies may be warranted [7]. To fill the gap of unexplained pain that is independent of disease activity measures, recent research has focused on additional pain mechanisms together with the contribution of psychosocial factors.

Several studies have shown abnormalities in peripheral and central nervous system (CNS) pain processing in patients with RA.

Meeus and colleagues [8] concluded in their systematic review that central sensitization (CS) can be present in people with RA. They assume that the main problem is the inflammation-evoked peripheral sensitization, leading to windup of the dorsal horn. Peripheral sensitization implies increased spontaneous activity, decreased activation threshold of nociceptive fibers, increased responsiveness to suprathreshold stimuli, and increased local release of neuropeptides on stimulation and recruitment of silent nociceptive fibers [9]. Due to this overload of nociceptive information, spinal neurons become sensitized, eventually leading to windup and long-term potentiation in the dorsal horn neurons and the brain [10-13]. CS represents an enhancement in the function of neurons and circuits in nociceptive pathways caused by increases in membrane excitability and synaptic efficacy as well as reduced inhibition and is a manifestation of the remarkable plasticity of the somatosensory nervous system in response to activity, inflammation, and neural injury [14]. As a consequence, a state of induced hypersensitivity of the pain system may persist in subsets of patients and lead to chronic pain states in which pain is no longer coupled to the presence of ongoing peripheral inflammation [15]. Changes in both the peripheral and central nervous system through processes of neural plasticity may thus play an important role in RA [5, 7, 15]. Among RA patients, pain thresholds, an index for pain sensitivity, seem to be lower at both joint and non-joint sites, in a widespread distribution, which is indicative of abnormalities in CNS pain processing [16-18]. The role of deficits in descending pain inhibition, measured by using the conditioned pain modulation paradigm, remains controversial. Lee et al. [18] observed that RA patients had impaired conditioned pain modulation compared with controls, while two smaller studies [13, 16] reported no statistically significant differences between RA patients and controls. Similar to this, the role of bottom-up hyperexcitability, measured by temporal summation, remains unclear as well. A study with 38 women with RA and 38 healthy controls demonstrated higher levels of temporal summation in RA patients [19], while Meeus et al. did not find significant differences between healthy controls and RA patients [20].

Maladaptive psychosocial factors have been repeatedly indicated to cause enhanced pain facilitation. Catastrophizing, the tendency to ruminate about and magnify pain, and depression, a more general mood disorder, are both risk factors for several adverse long- 
term pain-related outcomes in RA such as physical disability, increased severity of pain, and enhanced pain sensitivity [21]. In addition, Bagnato et al. [22] found that the more RA patients suffered from depression, the lower their pain thresholds were. Similar to depression, anxiety has also been associated with higher pain reports in cross-sectional analyses in RA patients [23].

Despite the need for future research to provide firm evidence in support of abnormalities in CNS pain processing, it is becoming clear that both peripheral and central mechanisms play key roles in the expression and consequences of pain in RA. In a subgroup of RA patients, CS could be the dominant pain mechanism, probably elicited by, but not directly related to ongoing inflammation [24]. Therefore, indices for CS are revealed in several studies explaining why a substantial proportion of RA patients in stable clinical remission continue to report moderate to severe pain levels $[4,25]$. The scope of the present paper will be the management of non-nociceptive pain mechanisms targeting central pain mechanisms, but in order to identify the most appropriate management plan for treating pain in RA patients, identification of the underlying predominant pain mechanism is of utmost importance. However, the classification between "dominant nociceptive pain" and "dominant CS pain" is clinically very challenging.

\section{Treatment}

Identification of the predominant pain mechanism in patients with RA

Patients with an unclear pain mechanistic background show the poorest response to medical treatment, because pain is not uniquely linked to disease activity. For the treatment of patients with CS, it is important to differentiate between rather "top-down" or "bottom-up" induced forms of CS. For the bottom-up form, or mainly peripherally driven form (i.e., driven by ongoing nociceptive input), the primary focus of interventions is to reduce peripheral nociceptive drive, eventually complemented with some more brain-oriented approaches. For the top-down form (i.e., brain-orchestrated) of CS, however, mainly CNS-directed therapies are needed to reduce pain and disability [26]. Neither is the identification of the dominating pain mechanism a binary approach (CS or no CS), nor does the more bottom-up or the more top-down form of CS occur in a black-or-white pattern. CS should therefore be seen as a continuum, rather than as a present/absent phenomenon. Consequently, patients will present mixtures of pain mechanisms along this continuum and treatment approaches need to balance between both peripherally and centrally targeted interventions. In patients with clear indications of abnormalities in CNS pain processing, treatment strategies should involve management of chronic pain, including treatment with classes of medication that target central pain mechanisms, pain neuroscience education (PNE), cognitive behavioral therapy (CBT), and graded activity (GA). These interventions aim to desensitize the CNS in contrast to therapeutic modalities that are only directed to structural joint pathology. Therapists should not only focus on medical treatment of the underlying disease [24]. But inversely, in a RA population, symptoms can be associated with but not uniformly characterized by CS. Therefore, a proper treatment approach starts with an appropriate pain analysis.

Currently, clinically relevant descriptors or screening tools that might indicate the presence of CS in patients with musculoskeletal pain, including RA, are still lacking $[15,27]$. Only a few studies have attempted to assess clinical indices of CS in RA, since RA has long been considered solely as a nociceptive pain condition. For patients with knee osteoarthritis (OA), Lluch et al. (2017) described a set of clinical descriptors that might help in the recognition and 
identification of CS. Since both RA and OA are local joint-related pain disorders, in which a subgroup can have CS as their dominant pain mechanism, the set of clinical descriptors for the recognition of CS in knee OA patients will be described below, including some recommended adjustments for the RA population. To facilitate a better overview, the descriptors are divided into two categories: descriptors extracted from the subjective assessment (subjective descriptors) and those from the physical examination (objective descriptors).

\section{Subjective assessment}

A patient-reported moderate to severe intensity of pain (VAS $>5 / 10$ ) can be a first cue for clinicians to be attentive for the existence of CS. Although this has not been specifically studied in RA patients so far, knee OA patients presenting signs of CS are more likely to present moderate to severe levels of pain [28, 29]. Secondly, if patients experience pain disproportionate to structural damage or pathology, it may raise suspicion about the presence of CS pain [30]. A third descriptor is to record the patients' pain distribution by asking them to draw their pain areas on a body chart. In knee OA patients, widespread nonanatomical distribution of pain seems to be a strong indicator of CS. RA patients typically present symmetrical polyarticular joint pain and swelling, mostly pronounced in the metacarpophalangeal (MCP) and proximal interphalangeal joints and the wrist [31]. Other frequently affected joints include the thumbs and metatarsophalangeal joints. Arthritis of medium/large joints can present early on in the elbows, shoulders, ankles, and knees, and is associated with more severe disease [32]. In addition, studies have indicated that RA leads to widespread pain in $10-20 \%$ of patients [33]. The symmetrical presentation of joint pain and the fact that RA is also characterized by symptoms that do not involve the joints make it hard for clinicians to determine whether widespread pain is due to disease characteristics or can be seen as a sign of altered central pain processing (CPP). Further, clinicians can be attentive to the pain pattern. In patients with RA, it is important to monitor the 24-h course of pain, to decide upon the inflammatory and/or mechanistic characteristics of the pain. Night pain and increased pain levels in the morning, for instance, are indicative for inflammatory pain, and for mechanic pain, there is a clear relation to movements and posture, while CS pain is less predictable and rather constant, vague, and dull [34]. Disproportionate and long-lasting pain after physical activity/ exercise might be indicative for CS as well. Centrally mediated symptoms (i.e., sleep disturbance, memory changes, fatigue) are often, but not exclusively seen in patients with CS. The central sensitization inventory (CSI) is a self-reported screening tool to administer symptoms associated with CS. A cutoff score of 40 out of 100 has been proposed [35], but not yet validated in different pain populations. Moreover, different researchers already advocated that the CSI is more likely to measure general distress [36]. Nevertheless, it can be useful to screen for non-musculoskeletal hypersensitivities (to bright light, stress, noise, etc.). A last subjective descriptor to account for is patients' responsiveness to previous treatment. Inconsistent, unpredictable, or unsuccessful reaction to nociception-targeted treatments might be attributable to the presence of CS. Clinicians must be attentive for this information when taking the patient history [37]. In RA patients, many studies have reported significant pain reduction associated with treatment with DMARDs [38]. However, many patients 
complain of residual pain despite treatment. This may be suggestive for the contribution of non-inflammatory factors to the expression of pain in RA [39, 40].

As mentioned above, psychosocial factors are of utmost importance and are known to explain some variation in pain reporting in RA. Lluch et al. (2017) have not included maladaptive psychological factors as clinical indicators of CS because they can be present in chronic pain patients without CS as well, making them an inappropriate indicator for CS. However, given the close association between maladaptive psychosocial factors (e.g., negative emotions, poor selfefficacy, maladaptive beliefs, and pain behaviors) and enhanced pain facilitation, assessing these factors might be helpful in order to establish an optimized pain management approach. Recently published "EULAR recommendations for the health professional's approach to pain management in inflammatory arthritis and osteoarthritis" also highlight the need to assess pain-related psychosocial factors [41]. Clinicians should assess important beliefs and emotions about pain such as the psychological response to pain and psychological vulnerability, psychological distress, psychiatric comorbidity, and cognitions such as catastrophizing (rumination, magnification, and helplessness), fear of movement-related pain, and pain self-efficacy. Also, social factors such as the way family members and other significant others react to patient's pain or pain-related disability, work, family and friends, economic problems, and housing might need attention [41]. Clinicians can use several questionnaires such as the Pain Catastrophizing Scale [42], the Tampa Scale for Kinesiophobia [43], and the pain self-efficacy questionnaire [44]. If there are indications that psychosocial factors interfere with effective pain management and functional status, referral to a psychologist should be considered (depending on the severity).

\section{Physical examination}

An inconsistent or confusing response to clinical tests during the physical examination may indicate the presence of CS [45]. Widespread hyperalgesia is a well-known feature of CS [45-47] and studies of experimental pain sensitivity have shown the presence of widespread distribution of hyperalgesia in RA patients compared with healthy controls [16, 17]. Thus, defining mechanical widespread hyperalgesia is another possible descriptor for the presence of CS. An algometer or manual palpation can be used for testing this widespread hyperalgesia. Allodynia, another hallmark sign of CS, has also been reported in RA patients [48] and can be measured using both static and dynamic stimuli by gently touching or brushing the skin with a cotton wool or a brush. Besides widespread mechanical hyperalgesia, heightened sensitivity to heat and cold stimuli, also considered an indicator of CS, has also been reported in RA patients $[16,17]$. Thermal widespread hyperalgesia in RA patients has been reported, and according to Maxwell and Sterling, who examined cold hyperalgesia in people with chronic whiplash-associated disorder, clinicians could be suspicious of the presence of cold hyperalgesia if pain $>5 / 10$ on a NRS after a $10 \mathrm{~s}$ of ice application [49]. Another clinical indicator of CS that has been shown to be present in RA patients is hypoesthesia. This can be tested by using a cotton wool over the involved joint(s) $[16,48]$. Despite the fact that the presence of temporal summation in RA patients remains unclear, it is a 
hallmark measure of CS so it may be useful for clinicians to identify using, for example, von Frey filaments or a small spring clamp [50].

The abovementioned subjective and objective descriptors should be considered as potential candidates that might be tested as future criteria for recognizing CS in RA patients as their psychometric properties (i.e., inter- and intraexaminer reliability, sensitivity, specificity) still have to be defined.

Once having analyzed the predominant pain mechanism, therapy can be tailored to the pain mechanism.

Since pharmacological treatment of RA has evolved tremendously during the last decades, and guidelines are available covering the use of traditional diseasemodifying antirheumatic drugs (DMARDs), biologic agents, tofacitinib, and glucocorticoid RA, there is sufficient information on the evidence-based, pharmacologic treatment of (nociceptive) pain in RA. Therefore, we will not focus on these topics, but rather the scope of the present article will be the management of non-nociceptive pain mechanisms targeting central pain mechanisms.

Peripheral nociceptive input in patients with CS pain can be decreased using pharmacological agents like non-steroidal anti-inflammatory drugs and coxibs. However, this medication will most often not result in amelioration of CS pain itself. Each of the following pharmacotherapies targets central pain processing mechanisms in animals and theoretically desensitizes the CNS in humans: acetaminophen, serotonin reuptake inhibitor drugs, selective and balanced serotonin and norepinephrine reuptake inhibitor drugs, the serotonin precursor tryptophan, opioids, combined $\mu$-opioid receptor agonist and noradrenaline reuptake inhibitor drugs, NMDA-receptor antagonists, and calcium channel a2d ligands. For a more thorough elucidation of pharmacotherapy potentially targeting CS pain, we refer to Nijs et al. [51].

Although in a subgroup of RA patients, pain is often related to noninflammatory factors, little research exists describing the best methods for managing this non-inflammatory pain in the RA population. Lee and colleagues [52] evaluated the efficacy of milnacipran, a serotonin norepinephrine reuptake inhibitor (SNRI), for treating widespread pain in RA. Milnacipran, the most recent FDA-approved drug for fibromyalgia, improved pain severity in randomized clinical trials of fibromyalgia [53-55]. Although milnacipran did not diminish pain in the overall RA study cohort compared with placebo, in a subgroup with well-controlled inflammatory disease (baseline swollen joint count $<1$ ), there was a significant reduction in pain measured using the Brief Pain Inventory. After 6 weeks, the difference between the decreases in pain intensity during milnacipran vs. placebo treatment was -1.14 points $(95 \% \mathrm{CI}$ $-2.26,-0.01)$. These findings suggest that milnacipran may be efficacious for RA patients with extremely well-controlled inflammation. It is important to realize that these pharmacological agents can have many side effects (e.g., fatigue, insomnia, tachycardia, gastrointestinal disturbances, headache). The possibility to treat the cause of pain must always be considered before entering the path of pharmacological symptomatic pain relief. In addition, high doses of opioid therapy can result in opioid-induced hyperalgesia [56]. Welsh et al. [57] for example found that the potential benefits of duloxetine and milnacipran in fibromyalgia were outweighed by their potential harms. Other treatment 
options, such as PNE, cognitive behavioral therapy, and multidisciplinary team rehabilitation, should be recommended as an alternative [58].

Education and exercise

Treatment of RA pain in case of dominant CS: "targeting the brain without ignoring the joints"

As stated above, it becomes clear that in a subgroup of RA patients, CNS

"desensitizing" strategies are necessary in order to decrease the amount of noninflammatory pain. Considering the role of peripheral sensitization caused by an overload of nociceptive information in the development of altered central pain processing, locally applied interventions to reduce peripheral nociceptive input are important as well. Therefore, in line with the practical guidelines for patients suffering knee OA with CS as their dominant pain mechanism [59], the authors of this paper recommend a combination of different strategies targeting the brain as well as the affected joints.

A first important step in effectively treating RA patients with CS as a dominant pain mechanism is educating patients and reconceptualizing pain by using a strategy known as pain neuroscience education (PNE). Research has repeatedly shown that PNE is therapeutic on its own, with a level A evidence, supporting its use for changing pain beliefs and improving health status in patients with CS pain $[60,61]$. It should be clear to patients that, in the case of CS, the brain is able to produce pain and other warning signs, even when there is limited or no tissue damage or nociception. By altering maladaptive pain beliefs and cognitions, PNE might be able to "treat" core features of CS, namely, descending nociceptive facilitation, endogenous analgesia, and the overactive pain neuromatrix [60]. The content of the education sessions can be based on the book Explain Pain (Butler and Moseley [62]), covering the physiology of the nervous system in general and of the pain system in particular. Table 1 shortly summarizes important steps of PNE [62, 63] (Table 1).

Further, based on level I evidence, cognitive behavioral therapy (CBT) is an effective intervention for managing pain in RA [41]. CBT focusses on changing unhelpful patterns of behavior and beliefs or attitudes toward RA. The education component focuses on helping patients change their negative perceptions regarding their abilities. It helps patients to develop a more optimistic but realistic attitude toward the illness and to manage other stresses in their lives. Strategies such as activity pacing, goal setting, problem solving, and relaxation strategies can be used to change behavior. In the case of RA, behavior change is usually helping patients to achieve a balance between rest and exercise. In their recent paper, Williams and Walsh [64] point out the importance of the balance between facilitating suppression of inflammatory disease activity and

Table 1. Short overview of the important steps of PNE

\section{PNE steps}

- Reconceptualizing pain by detailed pain education by using educational booklets, powerpoint, etc. - Ascertaining reconceptualization of pain by giving the patient homework such as reading the educational booklet carefully at home

- Application PNE during treatment (graded activity, time-contingent exercise therapy) 
discouraging deconditioning and concomitant augmentation of central pain processing. RA patients often show reduced physical activity levels due to movement-induced pain, fear that activity will aggravate their pain, or might induce a flare of inflammation. However, in healthy people and some RA patients as well [65], exercise activates powerful top-down pain inhibitory pathways after a submaximal cycling protocol, typically referred to as exerciseinduced endogenous analgesia (EIA) [65].

Therapeutic PNE prepares patients to a time-contingent, cognition-targeted approach to daily activity and exercise therapy $[51,59]$. When CS is present, a time-contingent graded activity or exercise approach is preferred over a symptom-contingent approach. Hence, clinicians should encourage patients to perform an activity/exercise (depending on status and goals of patient) for a specific time period regardless of the perceived pain, instead of using pain as guidance for exercise therapy. The advantage of a time-contingent approach is the possible deactivation of the brain-orchestrated top-down pain facilitatory pathways, whereas the symptom-contingent approach may facilitate the brain in its production of nonspecific warning signs [51].

Clinicians should bear in mind that although positive effects of long-term activity or exercise programs are found, a short-term exercise intervention may lead to pain exacerbations, increased pain sensitivity, bad recovery, etc. Thus, in the first phase of exercise programs, exercise-induced hyperalgesia may lead patients to attribute pain to exercise which can lead to avoidance of similar exercise in the future, comprising therapy compliance. Reduced or abnormal exercise may consequently lead to fear of movement and avoidance of certain activities and this may thus lead to further disuse, deconditioning, and further lowering of exercise tolerance [66]. This vicious circle can be an important therapy barrier so clinicians should take time exploring the patients' perceptions regarding anticipated outcomes of exercise bouts and the meaning of pain exacerbations. Therefore, the use of PNE prior to exercise therapy can be extremely helpful in addressing maladaptive pain beliefs in order to establish a natural reconceptualization of pain [67].

Specifically for RA patients, several systematic reviews have indicated the effectiveness of physical therapy for pain relief [68-71]. Increased physical activity and/or exercise may also have a protective effect on the cardiovascular system, improves disease-related outcomes including reductions in inflammation, and may be able to improve psychological health in those with RA. Moreover, aerobic and strengthening exercises do not exacerbate RA disease symptoms. A Cochrane review also recommends, with a level A evidence, aerobic capacity training in combination with muscle strength training as routine practice in patients with RA [72]. Thus, it can be stated that RA patients, whether or not they are showing features of altered CPP, benefit from exercise.

In conclusion, it is of great importance to recognize and identify the underlying dominant pain mechanisms in RA patients suffering chronic pain because non-inflammatory pain may have a serious negative impact on functionality and quality of life. Determining the predominant pain mechanism is important so that clinicians are able to provide a tailored treatment plan for RA patients suffering chronic pain. The treatment strategy should be matched to the predominant pain mechanism. Further, the authors of this review recommend a multidisciplinary approach including PNE, CBT, and a time-contingent activity/ exercise approach for treating CS in RA patients, on top of the typical diseasemodifying and eventual analgesic medication. However, it is important to note 
that there remains a need for randomized controlled trials to determine effective strategies for reducing CS in individuals with RA.

\section{Compliance with Ethical Standards}

\section{Conflict of Interest}

L. Meert declares that she has no conflict of interest. R. J. E. M. Smeets declares that he has no conflict of interest. I. Baert declares that she has no conflict of interest. M. Mertens declares that he has no conflict of interest. A. Boonen declares that she has no conflict of interest. M. Meeus declares that she has no conflict of interest.

\section{References and Recommended Reading}

1. Smolen JS, Aletaha D, McInnes IB. Rheumatoid arthritis. Lancet. 2016;388:2023-38.

2. Wan SW, He H-G, Mak A, Lahiri M, Luo N, Cheung PP, et al. Health-related quality of life and its predictors among patients with rheumatoid arthritis. Appl Nurs Res. 2016;30:176-83.

3. Furu M, Hashimoto M, Ito H, Fujii T, Terao C, Yamakawa N, et al. Discordance and accordance between patient's and physician's assessments in rheumatoid arthritis. Scand J Rheumatol. 2014;43:291-5.

4. Studenic P, Radner H, Smolen JS, Aletaha D. Discrepancies between patients and physicians in their perceptions of rheumatoid arthritis disease activity. Arthritis Rheum. 2012;64:2814-23.

5. Zhang A, Lee YC. Mechanisms for joint pain in rheumatoid arthritis (RA): from cytokines to central sensitization. Curr Osteoporos Rep. 2018;16:603-10.

6. Koop SMW, ten Klooster PM, Vonkeman HE, Steunebrink LMM, van de Laar MAFJ. Neuropathic-like pain features and cross-sectional associations in rheumatoid arthritis. Arthritis Res Ther. 2015;17:237. https://doi.org/10.1186/s13075-015-0761-8.

7. Boyden SD, Hossain IN, Wohlfahrt A, Lee YC. Noninflammatory causes of pain in patients with rheumatoid arthritis. Curr Rheumatol Rep. 2016;18:30.

8. Meeus M, Vervisch S, De Clerck LS, Moorkens G, Hans G, Nijs J. Central sensitization in patients with rheumatoid arthritis: a systematic literature review. Semin Arthritis Rheum. 2012;41:556-67.

9. Konttinen YT, Kemppinen P, Segerberg M, Hukkanen M, Rees R, Santavirta S, et al. Peripheral and spinal neural mechanisms in arthritis, with particular reference to treatment of inflammation and pain. Arthritis Rheum. 1994;37:965-82.

10. Hummel T, Schiessl C, Wendler J, Kobal G. Peripheral and central nervous changes in patients with rheumatoid arthritis in response to repetitive painful stimulation. Int J Psychophysiol. 2000;37:177-83.
11. Wendler J, Hummel T, Reissinger M, Manger B, Pauli E, Kalden JR, et al. Patients with rheumatoid arthritis adapt differently to repetitive painful stimuli compared to healthy controls. J Clin Neurosci. 2001;8:272-7.

12. García-Fernández E, Godoy-Izquierdo D, Pérez-García M, Jiménez-Alonso J, López-Chicheri I, Godoy JF. Differences in pressure-pain threshold between healthy women and patients with fibromyalgia syndrome, systemic lupus erythematosus, and rheumatoid arthritis. J Musculoskelet Pain. 2009;17:139-54.

13. Dhondt T, Willaeys LA, Verbruggen W. Pain threshold in patients with rheumatoid arthritis and effect of manual oscillations. Scand J Rheumatol. 1999;28:8893.

14. Latremoliere A, Woolf CJ. Central sensitization: a generator of pain hypersensitivity by central neural plasticity. J Pain. 2009;10:895-926.

15. Woolf CJ. Central sensitization: implications for the diagnosis and treatment of pain. Pain. 2011;152:S215.

16. Leffler A-S, Kosek E, Lerndal T, Nordmark B, Hansson $P$. Somatosensory perception and function of diffuse noxious inhibitory controls (DNIC) in patients suffering from rheumatoid arthritis. Eur J Pain. 2002;6:16176.

17. Edwards RR, Wasan AD, Bingham CO, Bathon J, Haythornthwaite JA, Smith MT, et al. Enhanced reactivity to pain in patients with rheumatoid arthritis. Arthritis Res Ther. 2009;11:R61.

18. Lee YC, Lu B, Edwards RR, Wasan AD, Nassikas NJ, Clauw DJ, et al. The role of sleep problems in central pain processing in rheumatoid arthritis. Arthritis Rheum. 2013;65:59-68.

19. Vladimirova N, Jespersen A, Bartels EM, Christensen AW, Bliddal H, Danneskiold-Samsøe B. Pain sensitisation in women with active rheumatoid arthritis: a comparative cross-sectional study. Arthritis. 2015;2015:1-5. https://doi.org/10.1155/2015/ 434109. 
20. Meeus M, Ickmans K, Struyf F, Hermans L, Noesel KV, Oderkerk J, et al. Does acetaminophen activate endogenous pain inhibition in chronic fatigue syndrome/ fibromyalgia and rheumatoid arthritis? A double-blind randomized controlled cross-over trial. Pain Physician. 2013 Apr;16(2):E61-70.

21. Edwards RR, Cahalan C, Mensing G, Smith M, Haythornthwaite JA. Pain, catastrophizing and depression in the rheumatic diseases. Nat Rev Rheumatol. 2011;7:216-24.

22. Bagnato G, De Andres I, Sorbara S, Verduci E, Corallo G, Ferrera A, et al. Pain threshold and intensity in rheumatic patients: correlations with the Hamilton Depression Rating scale. Clin Rheumatol.

2015;34:555-61.

23. Zyrianova Y, Kelly BD, Gallagher C, McCarthy C, Molloy MG, Sheehan J, et al. Depression and anxiety in rheumatoid arthritis: the role of perceived social support. Ir J Med Sci. 2006;175:32-6.

24. Rifbjerg-Madsen S, Christensen AW, Boesen M, Christensen R, Danneskiold-Samsøe B, Bliddal H, et al. The course of pain hypersensitivity according to painDETECT in patients with rheumatoid arthritis initiating treatment: results from the prospective FRAMEcohort study. Arthritis Res Ther. 2018;20:105. https:// doi.org/10.1186/s13075-018-1581-4.

25. Lee YC, Cui J, Lu B, Frits ML, Iannaccone CK, Shadick NA, et al. Pain persists in DAS28 rheumatoid arthritis remission but not in ACR/EULAR remission: a longitudinal observational study. Arthritis Res Ther. 2011;13:R83.

26. Harte SE, Harris RE, Clauw DJ. The neurobiology of central sensitization. J Appl Biobehav Res.

2018;23:e12137.

27. Curatolo M. Diagnosis of altered central pain processing. Spine. 2011;36:S200-4.

28. Arendt-Nielsen L, Egsgaard LL, Petersen KK, Eskehave TN, Nielsen TG, Hoeck HC, et al. A mechanism-based pain sensitivity index to characterize knee osteoarthritis patients with different disease stages and pain levels. Eur J Pain. 2015;19:1406-17.

29. Neogi T, Frey-Law L, Scholz J, Niu J, Arendt-Nielsen L, Woolf $\mathrm{C}$, et al. Sensitivity and sensitisation in relation to pain severity in knee osteoarthritis: trait or state? Ann Rheum Dis. 2015;74:682-8.

30. Nijs J, Torres-Cueco R, van Wilgen CP, et al. Applying modern pain neuroscience in clinical practice: criteria for the classification of central sensitization pain. Pain Physician. 2014;17:447-57.

31. Wasserman A. Diagnosis and Management of Rheumatoid Arthritis. AFP. 2011;84:1245-52.

32. Littlejohn EA, Monrad SU. Early diagnosis and treatment of rheumatoid arthritis. Prim Care. 2018;45:23755.

33. Wolfe F, Michaud K. Severe rheumatoid arthritis (RA), worse outcomes, comorbid illness, and sociodemographic disadvantage characterize RA patients with fibromyalgia. J Rheumatol. 2004;31:695700 .
34. Kolski M, O'Connor A. A world of hurt: a guide to classifying pain. St Louis: Thomasland Publishers, Inc; 2015.

35. Neblett R, Cohen H, Choi Y, Hartzell M, Williams M, Mayer TG, et al. The central sensitization inventory (CSI): establishing clinically significant values for identifying central sensitivity syndromes in an outpatient chronic pain sampje. J Pain. 2013;14:438-45.

36. Kregel J, Schumacher C, Dolphens M, Malfliet A, Goubert D, Lenoir D, et al. Convergent validity of the Dutch Central Sensitization Inventory: associations with psychophysical pain measures, quality of life, disability, and pain cognitions in patients with chronic spinal pain. Pain Pract. 2018;18:777-87.

37. Nijs J, Van Houdenhove B, Oostendorp RAB. Recognition of central sensitization in patients with musculoskeletal pain: application of pain neurophysiology in manual therapy practice. Man Ther. 2010;15:135-41.

38. Steiman AJ, Pope JE, Thiessen-Philbrook H, Li L, Barnabe C, Kalache F, et al. Non-biologic diseasemodifying antirheumatic drugs (DMARDs) improve pain in inflammatory arthritis (IA): a systematic literature review of randomized controlled trials. Rheumatol Int. 2013;33:1105-20.

39. McWilliams DF, Zhang W, Mansell JS, Kiely PDW, Young A, Walsh DA. Predictors of change in bodily pain in early rheumatoid arthritis: an inception cohort study. Arthritis Care Res (Hoboken). 2012;64:150513.

40. Altawil R, Saevarsdottir S, Wedrén S, Alfredsson L, Klareskog L, Lampa J. Remaining pain in early rheumatoid arthritis patients treated with methotrexate. Arthritis Care Res (Hoboken). 2016;68:1061-8.

41. Geenen R, Overman CL, Christensen R, et al. EULAR recommendations for the health professional's approach to pain management in inflammatory arthritis and osteoarthritis. Ann Rheum Dis. 2018;77:797-807. https://doi.org/10.1136/annrheumdis-2017-212662.

42. Sullivan MJL, Bishop SR, Pivik J. The Pain Catastrophizing Scale: development and validation. Psychol Assess. 1995;7:524-32.

43. Goubert L, Crombez G, Van Damme S, Vlaeyen JWS, Bijttebier P, Roelofs J. Confirmatory factor analysis of the Tampa Scale for Kinesiophobia: invariant twofactor model across low back pain patients and fibromyalgia patients. Clin J Pain. 2004;20:103-10.

44. Nicholas MK. The pain self-efficacy questionnaire: taking pain into account. Eur J Pain. 2007;11:153-63.

45. Courtney CA, Kavchak AE, Lowry CD, O'Hearn MA. Interpreting joint pain: quantitative sensory testing in musculoskeletal management. J Orthop Sports Phys Ther. 2010;40:818-25.

46. Suokas AK, Walsh DA, McWilliams DF, Condon L, Moreton B, Wylde V, et al. Quantitative sensory testing in painful osteoarthritis: a systematic review and metaanalysis. Osteoarthr Cartil. 2012;20:1075-85.

47. Arendt-Nielsen L, Skou ST, Nielsen TA, Petersen KK. Altered central sensitization and pain modulation in 
the CNS in chronic joint pain. Curr Osteoporos Rep. 2015; 13:225-34.

48. Hendiani JA, Westlund KN, Lawand N, Goel N, Lisse J McNearney T. Mechanical sensation and pain thresholds in patients with chronic arthropathies. J Pain. 2003;4:203-11.

49. Maxwell S, Sterling M. An investigation of the use of a numeric pain rating scale with ice application to the neck to determine cold hyperalgesia. Man Ther. 2013;18:172-4.

50. Neogi T, Guermazi A, Roemer F, Nevitt MC, Scholz J, Arendt-Nielsen L, et al. Association of joint inflammation with pain sensitization in knee osteoarthritis. Arthritis Rheumatol. 2016;68:654-61.

51. Nijs J, Malfliet A, Ickmans K, Baert I, Meeus M. Treatment of central sensitization in patients with 'unexplained' chronic pain: an update. Expert Opin Pharmacother. 2014;15:1671-83.

52. Lee YC, Massarotti E, Edwards RR, Lu B, Liu C, Lo Y, et al. The effect of milnacipran on pain in rheumatoid arthritis patients with widespread pain: a randomized blinded crossover trial. J Rheumatol. 2016;43:38-45.

53. Ormseth MJ, Eyler AE, Hammonds CL, Boomershine CS. Milnacipran for the management of fibromyalgia syndrome. J Pain Res. 2010;3:15-24.

54. Mease PJ, Clauw DJ, Gendreau RM, Rao SG, Kranzler J, Chen W, et al. The efficacy and safety of milnacipran for treatment of fibromyalgia. A randomized, doubleblind, placebo-controlled trial. J Rheumatol. 2009;36:398-409.

55. Clauw DJ, Mease P, Palmer RH, Gendreau RM, Wang Y. Milnacipran for the treatment of fibromyalgia in adults: a 15-week, multicenter, randomized, doubleblind, placebo-controlled, multiple-dose clinical trial. Clin Ther. 2008;30:1988-2004.

56. Mao J. Opioid-induced abnormal pain sensitivity: implications in clinical opioid therapy. Pain. 2002; 100:213-7.

57. Welsch P, Üçeyler N, Klose P, Walitt B, Häuser W. Serotonin and noradrenaline reuptake inhibitors (SNRIS) for fibromyalgia. Cochrane Database Syst Rev. 2018. https://doi.org/10.1002/14651858.CD010292. pub2.

58. Sluka K. Mechanisms and management of pain for the physical therapist. 2nd ed. Philadelphia: Wolters Kluwer Health; 2016.

59. Lluch Girbés E, Meeus M, Baert I, Nijs J. Balancing "hands-on" with "hands-off" physical therapy interventions for the treatment of central sensitization pain in osteoarthritis. Man Ther. 2015;20:349-52.

60. Oosterwijck JV, Meeus M, Paul L, Schryver MD, Pascal A, Lambrecht L, et al. Pain physiology education improves health status and endogenous pain inhibition in fibromyalgia. Clin J Pain. 2013;29:873-82.

61. Louw A, Diener I, Butler DS, Puentedura EJ. The effect of neuroscience education on pain, disability, anxiety, and stress in chronic musculoskeletal pain. Arch Phys Med Rehabil. 2011;92:2041-56.

62. Butler D, Moseley GL. Explain Pain, 2nd ed. Adelaide, Australia, Noigroup Publications. 2013

63. Nijs J, Paul van Wilgen C, Van Oosterwijck J, van Ittersum $M$, Meeus $M$. How to explain central sensitization to patients with 'unexplained' chronic musculoskeletal pain: practice guidelines. Man Ther. 2011;16:413-8.

64. McWilliams DF, Walsh DA. Pain mechanisms in rheumatoid arthritis. Clin Exp Rheumatol. 2017 Oct;35 Suppl 107(5):94-101.

65. Meeus M, Hermans L, Ickmans K, Struyf F, van Cauwenbergh D, Bronckaerts L, et al. Endogenous pain modulation in response to exercise in patients with rheumatoid arthritis, patients with chronic fatigue syndrome and comorbid fibromyalgia, and healthy controls: a double-blind randomized controlled trial. Pain Pract. 2015;15:98-106.

66. Vlaeyen JW, Linton SJ. Fear-avoidance and its consequences in chronic musculoskeletal pain: a state of the art. Pain. 2000;85:317-32.

67. Arendt-Nielsen L, and Perrot S. (2017). Pain in the joints. 1st ed. Philadelphia: Wolters Kluwer.

68. Park Y, Chang M. Effects of rehabilitation for pain relief in patients with rheumatoid arthritis: a systematic review. J Phys Ther Sci. 2016;28:304-8.

69. Ye L, Kalichman L, Spittle A, Dobson F, Bennell K. Effects of rehabilitative interventions on pain, function and physical impairments in people with hand osteoarthritis: a systematic review. Arthritis Res Ther. 2011;13:R28.

70. Vliet Vlieland TPM, van den Ende CH. Nonpharmacological treatment of rheumatoid arthritis. Curr Opin Rheumatol. 2011;23:259-64.

71. Metsios GS, Stavropoulos-Kalinoglou A, Kitas GD. The role of exercise in the management of rheumatoid arthritis. Expert Rev Clin Immunol. 2015;11:1121-30.

72. Hurkmans E, van der Giesen F, Vliet Vlieland T, Schoones J and Van den Ende E. Dynamic exercise programs (aerobic capacity and/or muscle strength training) in patients with rheumatoid arthritis. Cochrane Database of Systematic Reviews. 2009

\section{Publisher's Note}

Springer Nature remains neutral with regard to jurisdictional claims in published maps and institutional affiliations. 